\title{
Acute Cocaine Administration Depresses Cortical Activity
}

\author{
\begin{tabular}{l}
\hline Heather Trantham-Davidson' and Antonieta Lavin*,I \\
'Department of Physiology and Neuroscience, Medical University of South Carolina, Charleston, SC, USA \\
\hline
\end{tabular} \\ Psychostimulants, when administered acutely, produce significant deficits in cognitive tasks. Indeed, there is considerable evidence that \\ acute administration of cocaine alters cellular processes at the level of the nucleus accumbens and the ventral tegmental area (VTA). \\ However, there have been few studies that explore the acute effects of cocaine in the prefrontal cortex (PFC). Here we report that \\ acute cocaine administration in vivo evokes a prolonged membrane depolarization, decreases cortical spontaneous firing, compromises \\ spontaneous membrane bistability, and blunts the VTA-evoked responses in the PFC. Moreover, acute cocaine administration decreases \\ the amplitude of the EPSP-IPSP sequence that precedes the initiation of the Up states in the PFC, therefore compromising the driving \\ force of cortical bistability and thereby cortical excitability. \\ Neuropsychopharmacology (2004) 29, 2046-205I, advance online publication, 12 May 2004; doi: I 0. I 038/sj.npp. 1300482
}

Keywords: cocaine; prefrontal cortex; ventral tegmental area; excitability; cortical bistability

\section{INTRODUCTION}

The prefrontal cortex (PFC) is proposed to play a role in diverse cognitive functions such as working memory and attention (Williams and Goldman-Rakic, 1995; Yang et al, 1999). More recently, we and others have shown that repeated administration of drugs of abuse, such as cocaine, affect cellular (Trantham et al, 2002; Nasif et al, 2003) and metabolic functions (Grant et al, 1996; Childress et al, 1999; Volkow and Fowler, 2000) in the PFC. Moreover, it is known that psychomotor stimulants act on limbic and cognitive circuits, and drug-induced neuroadaptations in the corticolimbic circuits are increasingly gaining prominence in hypotheses of drug addiction (Pierce and Kalivas, 1997; Wolf, 1998; Jentsch and Taylor, 1999; Berke and Hyman, 2000).

There are considerable data indicating that repeated treatments with cocaine produce long-lasting cellular and metabolic changes in the PFC. Cocaine-induced neuroadaptations in the PFC have been proposed to play a role in behavioral sensitization and drug-seeking behavior (Pierce and Kalivas, 1997; Jentsch and Taylor, 1999; Nestler, 2001). Moreover, frontostriatal dysfunctions have been described in stimulant abusers (Jentsch and Taylor, 1999; Rogers et al, 1999; Ornstein et al, 2000; Grant et al, 2000). Neuroadaptations in dopamine (DA) transmission occur in the PFC as a consequence of repeated cocaine administration (Sorg et al, 1997); specifically, there is a reduction in both evoked DA release and DA content in the PFC of cocaine-treated

\footnotetext{
*Correspondence: Dr A Lavin, Department of Physiology and Neuroscience, Medical University of South Carolina, 173 Ashley Ave, Charleston, SC 29425, USA, Tel: + 843792 6799, Fax: 843792 4423, E-mail: lavina@musc.edu

Received 6 January 2004; revised 6 April 2004; accepted 8 April 2004 Online publication: 14 April 2004 at http://www.acnp.org/citations/ Npp04 | 40404005/default.pdf
}

animals (Masserano et al, 1994; Hedou et al, 2000). However, the acute administration of psychostimulants also produces important cognitive deficits. A recent study by Jentsch and colleagues (Jentsch et al, 2002) suggested that acute cocaine administration disrupts reversal learning in monkeys, although chronic treatment is required for longlasting deficits. Supporting their hypothesis that acutely administered cocaine is sufficient to alter learning, other investigators have shown that a single cocaine exposure can induce context-dependent behavioral sensitization (Jackson and Nutt, 1993; Alesdatter and Kalivas, 1993; Ungless et al, 2001).

There is considerable evidence that cocaine alters cellular processes at the level of the nucleus accumbens (NAc) and the ventral tegmental area (VTA). In fact, there is agreement that acute administration of psychostimulants primarily suppresses firing of NAc neurons in vivo (for a review, see White and Kalivas, 1998). Several ionic mechanisms are responsible for this suppression, including altered $\mathrm{K}^{+}$ conductances (Uchimura and North, 1990) and reduced whole $\mathrm{Na}^{+}$(Zhang et al, 1998) and $\mathrm{Ca}^{2+}$ conductances (Zhang et al, 2002). Moreover, Ungless et al (2001) have shown that a single in vivo exposure to cocaine induces long-term potentiation of AMPA-mediated currents at excitatory synapses of DA cells located in the VTA.

In contrast with the VTA and NAc, there have been few studies to explore the acute effects of cocaine in the PFC at the cellular level and, because even a single exposure to psychostimulants can alter the neurotansmitter balance in the PFC and produce profound alterations in the activity of cortical neurons and networks, it is clear that more studies are needed to address the acute effects of cocaine at the cortical level. Previously, we have reported that repeated cocaine administration decreases the number of cortical cells exhibiting membrane bistability (Trantham et al, 
2002). Here we report that acute administration of cocaine in vivo disrupts cortical membrane bistability, decreases spontaneous firing in cortical cells, and blunts VTA-evoked responses. Moreover, the cellular mechanisms that underlie the decrease in cortical bistability are explored.

\section{MATERIALS AND METHODS}

\section{Animal Preparation}

All animals were handled in accordance with the procedures outlined in the Guide for the Care and Use of Laboratory Animals published by the US Public Health Service, and the Medical University of South Carolina Animal Care and Use Committees approved the specific protocol. Subjects were male Sprague-Dawley rats (Harlan), weighing 200-250 g at the start of the experiment. Animals were housed in pairs in a temperature-controlled colony room on a 12-h light/dark cycle (lights on at $0700 \mathrm{~h}$ ) and food and water were available ad libitum. Animals were allowed to acclimatize to the colony room for 3-5 days after their arrival. Cocaine hydrochloride (COC) was donated generously by NIDA (Baltimore, MD). Cocaine was dissolved in $0.9 \%$ sterile saline and acutely administered (15 mg/kg, i.v.).

\section{Intracellular Recording}

The rats were anesthetized with chloral hydrate $(400 \mathrm{mg} / \mathrm{kg}$, i.p. (Sigma, St Louis, MO)), mounted in a stereotaxic apparatus (Narishige, Japan), and fitted with a lateral vein catheter for subsequent anesthetic or drug administration. The body temperature was maintained at $37 \pm 0.5^{\circ} \mathrm{C}$ by a thermostatically controlled heating pad (Harvard Apparatus). An incision was made in the scalp of each rat, the skull was exposed, and a burr hole was drilled overlying the PFC (coordinates from Bregma: AP: $+3.2 \mathrm{~mm}$; $L: 0.6 \mathrm{~mm}$; $V$ : $3.0-5.0 \mathrm{~mm}$ at $10^{\circ}$ inclination) and the VTA (coordinates from Bregma: AP: $-4.9 \mathrm{~mm}, L: 0.5 \mathrm{~mm}, V: 7.7 \mathrm{~mm}$ from the brain surface, Paxinos and Watson, 1998). Intracellular microelectrodes were pulled from $1.5-\mathrm{mm}$ outer diameter Omegadot tubing (WPI, New Haven, CT) using a Narishige vertical puller. The electrodes were filled with $3.0 \mathrm{M}$ potassium acetate (electrode resistance $=25-40 \mathrm{MOhms}$ in situ). Impalements were defined as stable if the resting membrane potential (RMP) was at least $-55 \mathrm{mV}$ and the action potential amplitude was at least $50 \mathrm{mV}$. A headstage amplifier connected to a preamplifier (NEURODATA IR-283, Cygnus Technology, Delaware Water Gap, PA) amplified the signals. Current was injected across a bridge circuit, with electrode potentials and current injection amplitude monitored on an oscilloscope (BKA Precision Instruments, Placentia, CA) using a National Instrument Board (National Instruments, BNC 2090) as an interface to a computer. Recorded data were stored on the hard drive of the computer for subsequent off-line analysis. Analysis was performed using a custom-designed software program. Input resistance (IR) was measured by passing pulses of depolarizing and hyperpolarizing current and measuring the voltage deflections during the steady state of the pulse. Electrical stimulation was delivered into the VTA by using bipolar concentric electrodes (Kopf, model SNE-10) delivering single current pulses with a duration of
$0.15 \mathrm{~ms}$, a frequency of $2 \mathrm{~Hz}$, and an amplitude of $3.0-$ $9.0 \mathrm{~mA}$. Spontaneous firing was monitored and recorded during baseline and following VTA stimulation. Acute cocaine injections were administered via the catheter fixed into the lateral tail vein. Once baseline recordings were performed $(10 \mathrm{~min})$, cocaine $(15 \mathrm{mg} / \mathrm{kg})$ was administered and spontaneous firing, VTA-evoked responses, IR, and membrane potential bistability were evaluated. Only one cell per animal was recorded.

\section{Histology and Statistics}

At the end of the experiments, the animals were given an overdose of anesthetic and perfused transcardially with saline, followed by $10 \%$ buffered formalin. The brain was removed and placed in a solution of $15 \%$ sucrose at $4{ }^{\circ} \mathrm{C}$. Coronal slices $60 \mu \mathrm{M}$ thick were cut using a freezing microtome and collected in phosphate buffer $(1.0 \mathrm{M}, \mathrm{pH}$ 7.4). The slices were stained with cresyl violet to aid in the localization of the electrode track and the stimulating electrode. The location of the track helped to identify the cortical layers in which the cells were recorded. There is extensive information regarding the electrophysiological characterization of pyramidal neurons and interneurons in the PFC (see Kawaguchi and Kubota, 1997; McCormick et al, 1985; Connors and Gutnick, 1990). Based on that information, we classified the neurons recorded as pyramidal cells. The spontaneous and evoked firing of neurons recorded in the PFC was compared using a two-tailed, two-sample, unequal variance Student's $t$-test. All data compared exhibited normal distributions. Statistical significance was set at $p<0.05$, and all results are presented as mean \pm SD.

\section{RESULTS}

A total of 20 pyramidal cells were recorded in the in vivo preparation. Only cells considered stable and healthy were included. In order to be included, the cells had to exhibit a resting membrane potential of at least $-55 \mathrm{mV}$, an action potential with amplitude of at least $50 \mathrm{mV}$, action potential duration of no more than $3 \mathrm{~ms}$, and have a stable baseline for at least $10 \mathrm{~min}$.

\section{Intrinsic and Synaptic Properties of Cortical Cells In Vivo}

The neurons recorded in the deep layers of the PFC exhibited an average membrane potential (MP) of $73.0 \pm$ $3.9 \mathrm{mV}(n=11$, non-bistable cells, Table 1$)$, and consistent with previous studies (Steriade et al, 1993; Lewis and O'Donnell, 2000; Trantham et al, 2002), 45\% of cortical neurons recorded in the in vivo preparation exhibited membrane bistability. Membrane bistability consisted of a depolarized phase with an average MP of $59.8 \pm 7.9 \mathrm{mV}$ $(n=9)$ and a hyperpolarized phase with an average MP of $71.0 \pm 8.3 \mathrm{mV}$ (Table 1, Figure 1a).

The average firing frequency of the cells was $4.1 \pm 2.2 \mathrm{~Hz}$ (Table 1). The neurons exhibited an average spike threshold of $51.7 \pm 2.8 \mathrm{mV}$ and an average input resistance (IR) of $55.7 \pm 12.3$ MOhms (Table 1). These electrophysiological properties were similar to those reported previously by our 
Table I Synaptic and Intrinsic Properties of Cortical Neurons Recorded In Vivo

\begin{tabular}{lcc}
\hline & Control & Cocaine \\
\hline Membrane potential $(\mathrm{mV})$ & $73.0 \pm 3.9(n=1 \mathrm{I})$ & $67.6 \pm 4.4(n=1 \mathrm{I})$ \\
Membrane potential Up states $(\mathrm{mV})$ & $59.8 \pm 7.9(n=9)$ & $62.2 \pm 10.8$ \\
Membrane potential Down state $(\mathrm{mV})$ & $71.0 \pm 8.3(n=9)$ & - \\
Cells exhibiting bistability & $45 \%(9 / 20)$ & $0 \%$ \\
Firing frequency (Hz) & $4.1 \pm 2.2(n=20)$ & $52.7 \pm 1.0 *(n=20)$ \\
Spike threshold $(\mathrm{mV})$ & $51.7 \pm 2.8(n=20)$ & $73.5 \pm 18.1(n=20)$ \\
Input resistance (MOhms) & $55.7 \pm 12.3(n=20)$ & $0.8 \pm 0.1 * *(n=13)$ \\
Rheobase current (mA) (VTA-evoked responses) & $0.6 \pm 0.2(n=13)$ & $5.5 \pm 1.6$ \\
Amplitude of VTA-evoked EPSPs & $4.5 \pm 1.5$ & $5.7 \pm 2.2 * *$ \\
Amplitude of VTA-evoked IPSPs & $8.6 \pm 2.2$ &
\end{tabular}

Data are presented as means \pm SD; $* p<0.03$; $* * * 0.001$.

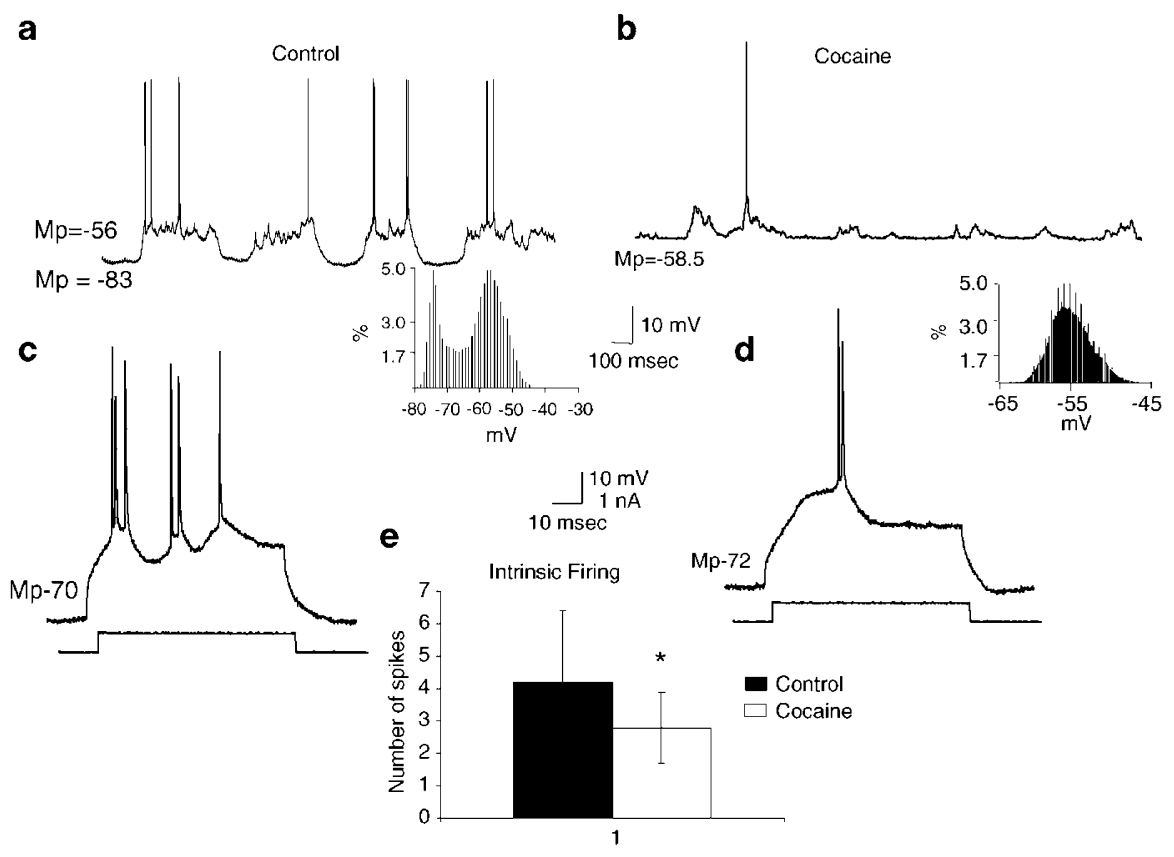

Figure I Acute cocaine administration decreases membrane bistability and cortical excitability in an in vivo preparation. (a) Spontaneous membrane bistability recorded intracellularly in a cortical neuron. The average membrane potential during the Down state was $-83 \mathrm{mV}$, the average membrane potential during the Up state was $-56 \mathrm{mV}$. The inset represents a membrane potential histogram that shows the membrane bistability exhibited by the cell. (b) At $10 \mathrm{~min}$ after cocaine administration ( $15 \mathrm{mg} / \mathrm{kg}$, i.v.), the bistable pattern was disrupted. The average membrane potential was $58.5 \mathrm{mV}$. The inset represents a membrane potential histogram that shows the unimodal distribution of membrane potential after cocaine administration. (c) Current injections evoked six action potentials in this cortical neuron during control recordings. (d) After cocaine administration ( $15 \mathrm{mg} / \mathrm{kg}$ i.v), the same current evoked only two action potentials. (e) The average intrinsic firing is significantly decreased after acute administration of cocaine $(4.1 \pm 2.8 \mathrm{vs} 2.7 \pm 1.0 \mathrm{~Hz}, p<0.02) \mathrm{Black}$ traces $=$ control recordings. Gray traces $=$ recordings after cocaine administration.

group and by others (Steriade et al, 1993; Lewis and O'Donnell, 2000; Trantham et al, 2002).

When electrical stimulation was delivered into the VTA, sequences of excitatory-inhibitory postsynaptic potentials (EPSP-IPSP), EPSPs, or IPSPs were evoked, depending on the state of the membrane potential at the time of the stimulation (Table 1, Figure 2). The average rheobase current for evoked responses was $0.6 \pm 0.2 \mathrm{~mA} \quad(n=13$, Table 1). The average amplitude for the EPSPs was $4.5 \pm$ $1.5 \mathrm{mV}$ and the average amplitude for evoked IPSPs was $8.6 \pm 2.2 \mathrm{mV}$ (Table 1 ). It has been shown that the VTAevoked sequence of EPSP-IPSPs underlies the initiation of the Up states in PFC (Seamans et al, 2003).

\section{Effects of Cocaine on Cell Membrane Properties and VTA-Mediated Responses in an In Vivo Preparation}

We investigated the actions of the psychostimulant cocaine on both cell membrane properties and synaptic-mediated responses of pyramidal cells within the PFC. Cocaine administration $(15 \mathrm{mg} / \mathrm{kg}$, i.v.) depolarized the MP of the nonbistable cells measured $10 \mathrm{~min}$ after cocaine administration (Table 1). More importantly, cocaine administration disrupted the bistability exhibited in nine cells (Figure 1). The average membrane potential of those cells was $62.2 \pm$ $10.8 \mathrm{mV}$ following cocaine administration (Table 1). Moreover, acute cocaine administration decreased significantly 
the spontaneous firing rate of pyramidal neurons. After $10 \mathrm{~min}$ of cocaine administration, the firing rate decreased from $4.1 \pm 2.2$ to $2.7 \pm 1.0 \mathrm{~Hz}\left({ }^{\star} p<0.03\right.$, Table 1, Figure 1). The neurons did not exhibit changes in average spike threshold (Table 1), but there is a trend for an increase in IR (Table 1).

Following acute administration of cocaine, the rheobase current needed to produce the VTA-evoked EPSP-IPSP sequence was significantly increased (control $0.6 \pm 0.2 \mathrm{~mA}$ $v s$ cocaine $0.8 \pm 0.1 \mathrm{~mA}, p<0.05$, Table 1 , Figure 2). Moreover, acute cocaine administration decreased the amplitude of the IPSP component on the VTA-evoked EPSP-IPSP sequence (control: $8.6 \pm 2.2$; cocaine $5.7 \pm 2.8, p<0.001$, Table 1, Figure 2).

\section{DISCUSSION}

Our results demonstrate that acute cocaine administration: (a) evokes a prolonged depolarization that resembles an Up state; (b) evokes a decrease in cortical firing rate; (c) reduces cortical responses to VTA stimulation; and (d)

a

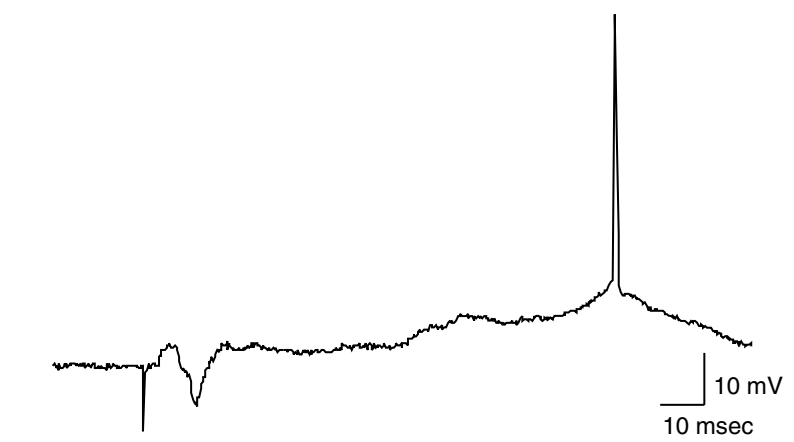

b

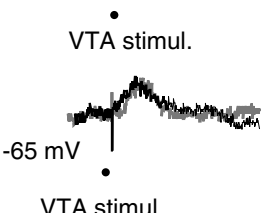

C

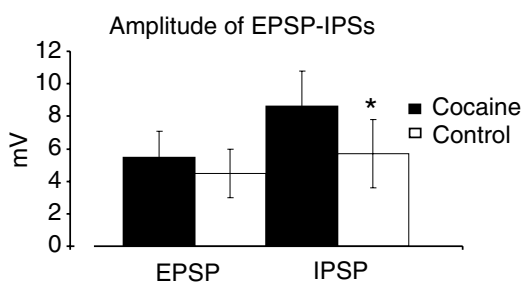

Figure 2 Electrical stimulation to the VTA-evoked sequences of EPSPIPSPs in an in vivo preparation. (a) Electrical stimulation in the VTA evoked an EPSP followed by an IPSP in an in vivo preparation. The EPSP has an onset latency of $2.5 \mathrm{~ms}$ and an amplitude of $2.5 \mathrm{mV}$. The IPSP has an onset latency of $5.0 \mathrm{~ms}$ and an amplitude of $5.3 \mathrm{mV}$. (b) Acute cocaine administration $(15 \mathrm{mg} / \mathrm{kg}$ ) did not affect the amplitude or the onset latency of the VTA-evoked EPSP; however, it decreased the amplitude of the VTAevoked IPSP (control: $2.6 \mathrm{mV}$ : cocaine $1.6 \mathrm{mV}$ ) without affecting onset latency. (c) Cocaine administration ( $15 \mathrm{mg} / \mathrm{kg}$ ) did not alter significantly the average amplitude of the VTA-evoked EPSP. In contrast, acute cocaine administration decreased the amplitude of the evoked IPSP $(p<0.05)$. Black traces $=$ control, Gray traces $=$ cocaine disrupts membrane bistability. Results obtained from analyzing the effects of acute cocaine in the VTA-evoked EPSPIPSP sequence indicate possible mechanisms underlying the decrease in spontaneous bistability and cortical activity. The acute dose of cocaine used in this study is comparable with the dose of cocaine that a rat will self-administer in a session of $2 \mathrm{~h}$ when in an FR1 schedule (average selfadministration $=19.2 \pm 1.4 \mathrm{mg} / \mathrm{kg} / \mathrm{session}$, Fuchs et al, 2004).

\section{Effects of Cocaine in Cell Membrane Properties and VTA-Evoked Responses}

In an in vivo preparation, acute cocaine administration disrupted spontaneous membrane bistability, produced a depolarization of the MP, and decreased cortical firing. Furthermore, after cocaine administration, the rheobase current needed to produce VTA-evoked responses was significantly increased. Indeed, following cocaine administration, the MP of the cortical cells appeared to enter into a prolonged Up state.

In 2000, Lewis and O'Donnell reported that chemical stimulation (local application of NMDA) of the VTA elicited a prolonged Up state in the PFC. Moreover, the long-lasting Up state was accompanied by a significant reduction in cortical firing. The authors hypothesized that activation of DA cells via NMDA receptors produce an evoked DA release in the PFC and this release of DA was responsible for the generation of a long-lasting Up state, through activation of DAD1 receptors in the PFC. Regarding the decrease in cortical firing rate, the authors proposed that the evoked release of DA decreased firing rate via DA actions on $\mathrm{Na}^{+}$channels. From the Lewis and O'Donnell paper, it is also clear that while DA did not mediate the Up states, it did contribute to the maintenance and duration of the depolarizations.

Our results suggest that acute administration of cocaine, by increasing DA release in the PFC (Pan et al, 1995; Maisonneuve et al, 1990), produces a prolonged membrane depolarization that resembles a long-lasting Up state. That is, cortical cells are switched from a bistable state to a prolonged depolarized Up state by the acute cocaineinduced increase in DA. This excess DA acts then through stimulation of DAD1 receptors. Furthermore, the increase in cortical DA may also be responsible for the decrease in spontaneous firing via mechanisms similar to the one proposed by Lewis and O'Donnell; thus, DA may decrease the cortical firing rate by reducing whole sodium and calcium currents, as proposed by Zhang et al (1998, 2002). However, this point is controversial, because Yang and Seamans (1996) have shown that DA increases persistent sodium currents in PFC by acting through DAD1 receptors. In fact, a more plausible explanation for the decrease in cortical firing may be related to the DAergic effect on DAD2 cortical receptors, as discussed below.

In addition to the disruption of cortical bistability, this report provides evidence that cortical cells in vivo exhibited a blunted response to electrical stimulation delivered into the VTA following cocaine administration. It is important to indicate that DA can exert bi-directional effects: it can increase and decrease neuronal excitability depending on the concentration. It is known that in PFC, activation of DAD1 receptors increases cortical activity, whereas 
activation of DAD2 receptors decreases activity (Yang and Seamans, 1996). Moreover, recent experiments by our lab (Trantham-Davidson et al, 2003) provide evidence that low doses of DA in PFC activate only D1 type receptors, whereas high doses activate $\mathrm{DAD} 2$ receptors that are known to decrease cortical activity. As mentioned before, it has been shown that acute cocaine administration increases extracellular DA in the PFC. This excess DA could stimulate DAD2 cortical receptors that are known to decrease cortical activity, therefore blunting cortical responses evoked by VTA stimulation and also decreasing spontaneous firing. Nevertheless, it is also possible to propose that systemic administration of cocaine is affecting serotonin and noradrenaline $(\mathrm{NE})$, and that some of the effects reported here are mediated through these other monoamines. In fact, Waterhouse et al (1996) have shown that, in the somatosensory cortex, cocaine facilitates effects on long-latency responses to receptive field stimulation through a 5-HTdependent mechanism. On the other hand, cocaine enhances the excitatory actions of $\mathrm{NE}$ in the dorsal raphe by acting through alpha 1 receptors (Oleskevich and Williams, 1995). However, to date, no data have been published regarding the physiological effects of acute cocaine on 5-HT or NEmediated responses in PFC.

It is important to note that some of the VTA-evoked responses could be due to antidromic activation of the PFCVTA pathway. However, we believe that this is unlikely, because previous work by our lab has shown that 6-OHDA lesions of the VTA abolish the VTA-evoked EPSP-IPSPs (Lavin et al, 2002). Moreover, we have shown (Lapish et al, 2003) that TTX applied to the medial forebrain bundle (MFB) abolishes the VTA-evoked EPSP. The MFB carries the VTA-PFC innervation but not the PFC-VTA pathway, which travels through the cerebral peduncle.

We have previously reported that stimulation of afferent inputs to cortical cells evoked sequences of EPSP-IPSPs that contribute to the Up state (Seamans et al, 2003). In that report, we showed that the onset of the Up state is mediated by a glutamatergic drive that in turn mediated the GABAdependent EPSP-IPSP sequence. Now, we present evidence that acute cocaine decreases the amplitude of the first component of the Up state: the sequence of EPSP-IPSPs. Thus, we speculate that the driving force of the Up state is compromised by acute cocaine administration, thereby decreasing the probability that cortical bistability can be established.

\section{Functional Implications}

Addressing the cellular effects of acute cocaine administration provides insights into the basic mechanism modulating the long-lasting effects of repeated administration. Furthermore, transient changes in cortical excitability may have a role in mediating some of the short-term behavioral effects of cocaine. For example, acute cocaine administration to monkeys has been shown to impair performance in a behavioral paradigm that involves new learning as well as behavioral flexibility (Thompson and Moerschbaecher, 1970; Evans and Wenger, 1992; Jentsch et al, 2002). The cocaine-induced decrease in cortical bistability reported here could contribute to decrease efficiency of information processing in prefrontal cortex and compromise functions such as working memory and attention.

\section{ACKNOWLEDGEMENTS}

We thank Dr Peter W Kalivas for insightful discussions and support. We also thank Dr Jennifer G Schnellmann for her help in correcting and editing this manuscript. This research is supported by National Institutes of Health grant DA 14698 (AL) and P50DA015369 (AL).

\section{REFERENCES}

Alesdatter JE, Kalivas PW (1993). Inhibition of mu opioid-induced motor activity in the ventral pallidum by $\mathrm{D} 1$ receptor blockade. Behav Pharmacol 4: 645-651.

Berke JD, Hyman SE (2000). Addiction, dopamine, and the molecular mechanism of memory. Neuron 25: 15-32.

Childress AR, Mozley PD, McElgin W, Fitzgerald J, Reivich M, O'Brien CP (1999). Limbic activation during cue-induced cocaine craving. Am J Psychiatry 156: 11-18.

Connors BW, Gutnick MJ (1990). Intrinsic firing patterns of diverse neocortical neurons. Trends Neurosci 13: 99-104.

Evans EB, Wenger GR (1992). Effects of drugs of abuse on acquisition of behavioral chains in squirrel monkeys. Psychopharmacology 107: 55-60.

Fuchs RA, Evans KA, Parker MC, See RE (2004). Differential involvement of the core and shell subregions of the nucleus accumbens in conditioned cue-induced reinstatement of cocaine seeking in rats. Neuropsychopharmacology, In press.

Grant S, Contoreggi C, London ED (2000). Drug abusers show impaired performance in a laboratory test of decision making. Neuropsychologia 38: 1180-1187.

Grant S, London ED, Newlin DB, Villemagne VL, Liu X, Contoreggi $C$ et al. (1996). Activation of memory circuits during cue-elicited cocaine craving. Proc Natl Acad Sci USA 93: 12040-12045.

Hedou G, Homberg J, Martin S, Wirth K, Feldon J, Heidbreder CA (2000). Effects of amphetamine on extracellular acetylcholine and monoamine levels in subterritories of the rat medial prefrontal cortex. Eur J Pharmacol 390: 127-136.

Jackson HC, Nutt DJ (1993). A single preexposure produces sensitization to the locomotor effects of cocaine in mice. Pharmacol Biochem Behav 45: 733-735.

Jentsch JD, Olausson P, De La Garza R, Taylor JR (2002). Impairments of reversal learning and response perseveration after repeated, intermittent cocaine administrations to monkeys. Neuropsychopharmacology 26: 183-190.

Jentsch JD, Taylor JR (1999). Impulsivity resulting from frontostriatal dysfunction in drug abuse: implications for the control of behavior by reward-related stimuli. Psychopharmacology 146: 373-390.

Kawaguchi Y, Kubota Y (1997). GABAergic cell subtypes and their synaptic connections in rat frontal cortex. Cerebral Cortex 7: 476-486.

Lapish C, Nogueira L, Lavin A, Seamans JK (2003). Fast neurotransmission in the VTA-prefrontal pathway. Soc Neurosc Abst 720.

Lavin A, Nogueira L, Berglind W, Seamans JK (2002). Characterization of cortical responses mediated by VTA stimulation. Soc Neurosc Abst 336.

Lewis BL, O'Donnell P (2000). Ventral tegmental area afferents to the prefrontal cortex maintain membrane potential 'Up' states in pyramidal neurons via D1 dopamine receptors. Cerebral Cortex 10: $1168-1175$.

Maisonneuve IM, Keller RW, Glick SD (1990). Similar effects of Damphetamine and cocaine on extracellular dopamine levels in medial prefrontal cortex of rats. Brain Res 535: 221-226. 
Masserano JM, Venable D, Wyatt RJ (1994). Effects of chronic cocaine administration on $[3 \mathrm{H}]$ dopamine uptake in the nucleus accumbens, striatum and frontal cortex of rats. J Pharmacol Exp Ther 270: 133-141.

McCormick DA, Connors BW, Lighthall JW, Prince DA (1985). Comparative electrophysiology of pyramidal and sparsely spiny stellate neurons in the neocortex. J Neurophysiol 54: 782-806.

Nasif FJ, Sidiropoulu K, Hu X, White FJ (2003). Increased excitability on medial prefrontal cortex pyramidal neurons after long-term withdrawal from repeated cocaine administration. Neurosci Abst 321.

Nestler EJ (2001). Neurobiology. Total recall-the memory of addiction. Science 292: 2266-2267.

Oleskevich S, Williams JT (1995). Cocaine prolongs norepinephrine potentials in rat dorsal raphe. J Neurophysiol 73: 687-692.

Ornstein TJ, Iddon JL, Baldacchino AM, Sahakina BJ, London M, Everitt BJ et al. (2000). Profiles of cognitive dysfunction in chronic amphetamine and heroin abusers. Neuropsychopharmacology 23: 113-126.

Pan WH, Lai YJ, Chen NH (1995). Differential effects of chloral hydrate and pentobarbital sodium on a cocaine level and its catecholamine responses in the medial prefrontal cortex: a comparison with conscious rats. J Neurochem 64: 2653-2659.

Paxinos G, Watson C (1998). The Rat Brain in Stereotaxic Coordinates, 4th edn. Academic Press: San Diego, CA.

Pierce RC, Kalivas PW (1997). A circuitry model of the expression of behavioral sensitization to amphetamine-like psychostimulants. Brain Res Rev 25: 192-216.

Rogers RD, Everitt BJ, Baldacchino A, Blackshaw AJ, Swainson R, Wynne $\mathrm{K}$ et al. (1999). Dissociable deficits in the decisionmaking cognition of chronic amphetamine abusers, opiate abusers, patients with focal damage to prefrontal cortex, and tryptophan-depleted normal volunteers: evidence for monoaminergic mechanism. Neuropsychopharmacology 20: 322-339.

Seamans JK, Nogueira L, Lavin A (2003). Synaptic basis of persistent activity in prefrontal cortex. Cerebral Cortex 13: 1242-1250.

Sorg BA, Davidson DL, Kalivas PW, Prasad BM (1997). Repeated daily cocaine alters subsequent cocaine-induced increase in extracellular dopamine in the medial prefrontal cortex. $J$ Pharmac Exp Ther 281: 54-61.

Steriade M, Nunez A, Amizca F (1993). A novel slow $(<1 \mathrm{~Hz})$ oscillation of neocortical neurons in vivo: Depolarizing and hyperpolarizing components. J Neurosci 13: 3252.

Thompson DM, Moerschbaecher JM (1970). An experimental analysis of the effects of D-amphetamine and cocaine on the acquisition and performance of response chains in monkeys. J Exp Anal Behav 32: 433-444.

Trantham H, Szumlinski KK, McFarland K, Kalivas PW, Lavin A (2002). Repeated cocaine administration alters the electrophysiological properties of prefrontal cortical neurons. Neuroscience 113: $49-753$.

Trantham-Davidson H, Lavin A, Seamans JK (2003). Concentration specific modulation of $\mathrm{GABA}_{\mathrm{A}}$ currents in prefrontal neurons via different dopamine receptors subtypes. Soc Neurosc Abst 573.

Uchimura N, North RA (1990). Actions of cocaine on rat nucleus accumbens neurons in vitro. Br J Pharmacol 99: 736-740.

Ungless MA, Whistler JL, Malenka RC, Bonci A (2001). Single cocaine exposure in vivo induces long-term potentiation in dopamine neurons. Nature 411: 583-587.

Volkow ND, Fowler JS (2000). Addiction, a disease of compulsion and drive: involvement of the orbitofrontal cortex. Cerebral Cortex 10: 318-325.

Waterhouse BD, Gould EM, Bekavac I (1996). Monoaminergic substrates underlying cocaine-induced enhancement of somatosensory-evoked discharges in rat barrel field cortical neurons. $J$ Pharmacol Exp Ther 279: 582-592.

White FJ, Kalivas PW (1998). Neuroadaptations involved in amphetamine and cocaine addiction. Drug Alcohol Depend 51: 141-153.

Williams GW, Goldman-Rakic PS (1995). Modulation of memory fields by dopamine D1 receptors in prefrontal cortex. Nature 376: $572-575$.

Wolf ME (1998). The role of excitatory amino acids in behavioral sensitization to psychomotor stimulants. Prog Neurobiol 54: $1-42$.

Yang CR, Seamans JK (1996). Dopamine D1 receptor actions in layers $\mathrm{V}$-VI rat prefrontal cortex neurons in vitro: modulation of dendritic-somatic signal integration. J Neurosci 16: 1922-1935.

Yang CR, Seamans JK, Gorelova N (1999). Developing a neuronal model for the pathophysiology of schizophrenia based on the nature of electrophysiological actions of dopamine in the prefrontal cortex. Neuropsychopharmacology 21: 161-194.

Zhang XF, Cooper DC, White FJ (2002). Repeated cocaine treatment decreases whole-cell calcium current in rat nucleus accumbens neurons. J Pharmacol Exp Ther 1: 1119-1125.

Zhang XF, Hu XT, White FJ (1998). Whole-cell plasticity in cocaine withdrawal: reduced sodium current in nucleus accumbens neurons. J Neurosci 18: 488-498. 